\title{
The Contribution of Computerized Tomography in Diagnostic Skeletal Imaging in Acute Spinal Cord Injury*
}

C. E. Seibert, M.D., J. N. Dreisbach, M.D., H. R. Hahn, M.D. and C. Brown, M.D.

Radiology Imaging Associates P.C., Englewood, Colorado, 80110, U.S.A.

Key words: Acute Spinal Injury; Spinal Computerised Tomography.

The authors summarise their findings in use of computerised tomography (C.T.) in she initial evaluation of 119 spinal cord injured patients admitted to the Rocky Mountain Regional Spinal Cord Injury System from May, 1979 through to October, 1983. Of the 119 patients, $47(40 \%)$ had CT during the initial evaluation of their injury. (32 of 67 paraplegics and 11 of 52 tetraplegics had high resolution CT scans).

Prior to August, 1981, EMI-5005 scanners were available but were used sporadically because of factors discussed below. In 1981, the GE 8800 CT became available for use and subsequently largely replaced tomography in the evaluation of thoracic lumbar injury and was used frequently in cervical injury. Technical requirements for useful CT were found to be: sagittal and coronal reformatting capability; rapid scanning; thin sections of $1.5 \mathrm{~mm}$ for cervical studies and 5 $\mathrm{mm}$ for lumbar thoracic studies with overlapping for reformatting; extended bone window; and digital radiographic views.

Advantages of CT over tomography included not having to turn the patient for the lateral examination, thus increased safety; diminished $\mathrm{X}$-ray exposure dose for CT as compared with tomography: CT: approximately $2-4 \mathrm{r} /$ examination tomography: approximately $75-100 \mathrm{r} /$ examination. Additionally, CT was advantageous for the visualization of the $\mathrm{C} 7, \mathrm{~T} 1 \mathrm{level}$; for display of the posterior vertebral elements and arch: for evaluation of canal integrity; unsuspected fractures and fracture fragments and tracking of missile paths. Orthopaedic surgeons found thoracic lumbar CT helpful for planning spine stabilisation, and for the approach for reduction of canal fragments.

The authors conclude that following plain X-ray films, CT is the radiographic procedure of choice in the evaluation of the vertebral column in spinal cord injury.

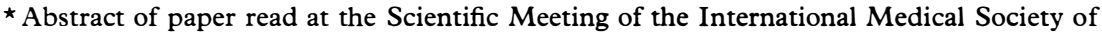
Paraplegia, Denver, Colorado, U.S.A., June, 1984.
} 